\title{
MEJORAMIENTO TÉRMICO y capacidad de MITIGACIÓN CLIMÁTICA DE LA CUBIERTA VERDE
}

\section{en vivienda en zonas áridas}

\author{
Thermal improvement and mitigation of green roof in housing in arid areas
}

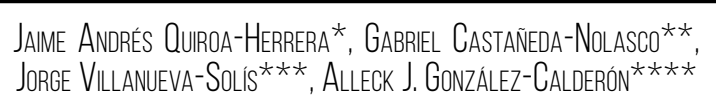

RESUMEN. En este artículo se analiza experimentalmente el comportamiento térmico y la capacidad de mitigación climática de la cubierta verde aplicada a una vivienda de interés social de las que se producen en Torreón, Coahuila. En la zona de estudio, el clima es de árido a semiárido. Se identificó una vivienda y se instaló la cubierta verde para analizarla experimentalmente. Para el registro de las mediciones internas de temperatura se utilizó equipos ново U12, para el registro de las temperaturas externas se empleó también un sensor ново Pro V2 con abrigo de protección externo. Los datos obtenidos de las mediciones realizadas en la vivienda se graficaron en Excel y fueron analizados e interpretados de acuerdo con el método de la climatología dinámica y los episodios de tiempo. Los resultados obtenidos muestran que al igual que en los módulos a escala utilizados en un proyecto previo, en la vivienda analizada, la cubierta verde es una tecnología que además de mejorar las condiciones térmicas, se muestra como una estrategia eficiente de mitigación climática para su aplicación en viviendas nuevas o existentes de la región.

Palabras clave: Comportamiento térmico, mitigación climática, cubierta verde, vivienda, zonas áridas.
Fecha de recibido:

11 Septiembre 2020

Fecha de aceptado:

4 Marzo 2021
*Universidad Autónoma de Coahuila, México. jquiroa@uadec.edu.mx

**Universidad Autónoma de Chiapas, México. gnolasco2@gmail.com

***Universidad Autónoma de Coahuila, México. jorge.villanueva@uadec.edu.mx

****Universidad Autónoma de Coahuila, México. alleck.gonzalez@uadec.edu.mx

ABSTRACT. In this article, the thermal behavior and mitigation capacity of the green roof applied to a low-income housing produced in Torreón, Coahuila, were experimentally analyzed. In the study area the climate is from arid to semi-arid. A house was identified, and the green roof was installed to analyze it experimentally. НОво U12 equipment was used to record the internal temperature measurements, a ново Pro V2 sensor with an external protective coat was also used to record the external temperatures. The data obtained from the measurements carried out in the home were graphed in Excel and were analyzed and interpreted according to the method of dynamic climatology and time episodes. The results obtained show that, as in the scale modules used in the previous project, in the house analyzed, the green roof is a technology that, in addition to improving the thermal conditions of the house, is shown as a highly efficient mitigation strategy climate for its application in new or existing homes in the region.

Key words: Thermal behavior, climate mitigation, green roof, housing, arid zones. 


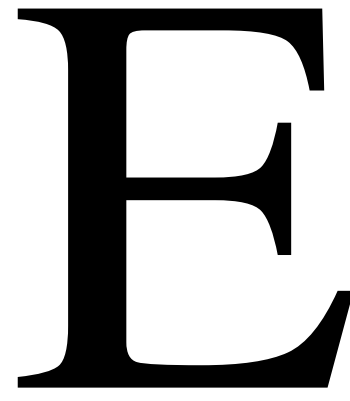

1 presente trabajo analiza experimentalmente la eficiencia térmica y la capacidad de mitigación de la

cubierta verde ligera instalada en una vivienda de interés social de las que se producen en la región de Torreón Coahuila.

La zona de estudio tiene un clima de árido cálido, con una media de precipitación anual de $250 \mathrm{ml}$. De acuerdo con el Plan Estatal contra el Cambio Climático en Coahuila, se prevé un incremento de SEMA (2016), uno de los efectos en la región será el incremento de las temperaturas. También Intergovernmental Panel on Climate Change (IPCC, 2019) prevé un incremento de $1.5{ }^{\circ} \mathrm{C}$ como una de las afectaciones del cambio climático. Esta situación sumada a las condiciones de la región, tendrían efectos directos en diferentes sectores entre los cuales está el de la vivienda y que al no estar correctamente adaptada a las condiciones actuales o previstas significaría una afectación directa a los usuarios de ésta.

Aunado a esto, el Instituto del Fondo Nacional de la Vivienda (INFONAVIT, 2013) 
En este proyecto participaron

INVESTIGADORES DE CUATRO UNIVERSIDADES DEL PAÍS, una de las

experiencias se desarrolló en TORREÓN,
COAHUILA,

EN LA ESCUELA DE ARQUUTECTURA DE LA UNIVERSIDAD AUTÓNOMA

DE COAHUILA.

menciona que en los próximos años existirá un incremento en la demanda de las viviendas a nivel nacional, esto, sumado al déficit de vivienda existente en el país. De igual forma, el acuerdo al Diario Oficial de la Federación (DOF, 2014) menciona que este déficit, en el 2012, ascendió a las 15 millones. Según la Sociedad Hipotecaria de la Federación (2020), para el 2018 existió un rezago habitacional de 9.4 millones de vivienda y de acuerdo con la Comisión Nacional de Vivienda (CONAvi) para el 2020 el rezago fue de 8.5 millones (Díaz Duarte et al., 2021).

El déficit existente aunado al incremento de la demanda, evidencia la

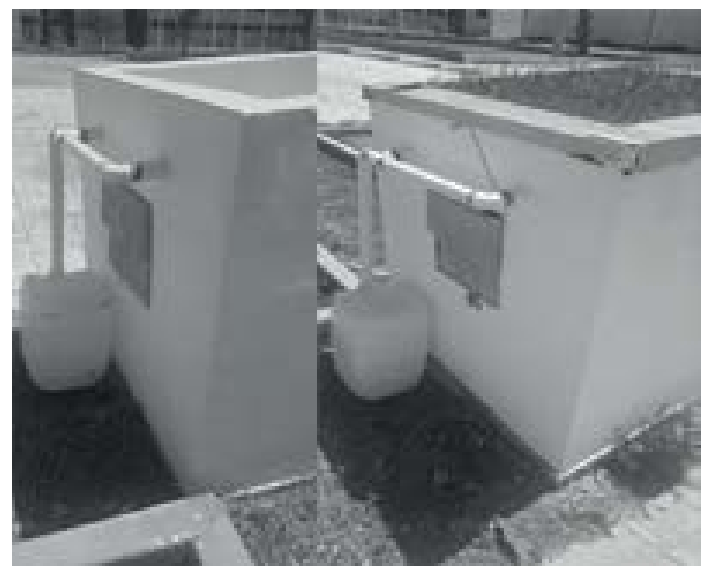

FIGURA 1. PROTOTIPOS EXPERIMENTALES CON $1 M^{3}$ DE VOLUMEN DE AIRE INTERNO PARA EL ANÁLISIS DE LA CUBIERTA VERDE LIGERA, EN TORREÓN COAHUIILA. FUENTE: ELABORACIÓN PROPIA. necesidad de impulsar políticas públicas de vivienda sustentable, como lo menciona la conavi (2014), dicha propuesta está orientada a que se generen viviendas nuevas y existentes con mejores estándares de calidad de vida.

Lo anterior, evidencia la necesidad de adaptar la vivienda existente y nueva no sólo a las condiciones actuales, sino también a las posibles variaciones que puedan presentarse a futuro, esto se podrá lograr investigando y desarrollando tecnologías que contribuyan en este aspecto, el IPCC generó un reporte en el cual uno de los sectores a los que se refiere es el residencial y señala las mejoras exteriores de los edificios para reducir la ganancia de calor (Watson, Zonyowera \& Moss, 1996), tomando en cuenta esto, además de contribuir a la eficiencia térmica del edificio también sería una estrategia de mitigación, ya que se estaría evitando la ganancia térmica y disminuyendo el consumo energético, reduciendo así la emisión de gases de efecto invernadero (IPCC, 2001).

\section{ANTECEDENTES}

La propuesta y desarrollo de cubiertas verdes ha sido una tecnología alternativa, que fue utilizada y estudiada en diferentes regiones, en la literatura son reconocidos los beneficios de la aplicación y utilización de las cubiertas verdes, entre los principales se pueden mencionar: el aspecto térmico y su contribución al ahorro de electricidad (Trujillo Samayoa et al., 2015) (Jim, 2014) o como estrategia de resiliencia ante el cambio climático (Razzaghmanesh, Beecham \& Brien, 2014) como estrategia contra inundaciones (Cook \& Larsen, 2021), además, puede contribuir a la reducción de emisiones de dióxido de carbono por la disminución del consumo energético y por el absorbido por la vegetación de éste por medio proceso de fotosíntesis (Reza et al., 2021).

Se tiene como antecedente previo el ensayo experimental de cubiertas verdes 
en climas tropicales (Vecchia, Castañeda \& Quiroa, 2006), así como el proyecto "Adaptación de techo verde aplicable a la vivienda de interés social" PINCC-UNAM. En este último, se estudió la propuesta de una cubierta verde ligera como propuesta para su aplicación en vivienda de interés social existente, en donde se utilizaron módulos experimentales a escala y de $1 \mathrm{x} 1$ con materiales empleados en vivienda en Torreón (Quiroa Herrera, J. A.; Castañeda Nolasco, G.; Villanueva Solis, J., 2020), que fue una de las ciudades de estudio junto con Oaxaca, Mérida, Guerrero y Chiapas.

En este proyecto participaron investigadores de cuatro universidades del país, una de las experiencias se desarrolló en Torreón, Coahuila, en la Escuela de Arquitectura de la Universidad Autónoma de Coahuila (figura 1).

\section{METODOLOGÍA}

\section{SELECCIÓN DE VIVIENDA}

Para la selección de vivienda, se tomaron los siguientes criterios:

1. Ser una vivienda de interés social.

2. Asumir las características de la vivienda de interés social que se produce en la región.

3. Tener entre los 45 a $55 \mathrm{~m}^{2}$ de construcción.

Con el apoyo del InfonAvit, se contactó a una de las empresas más representativas en producción de vivienda en la zona de estudio, cuyo nombre es RUBA, dicha empresa facilitó una de las viviendas que produce en la región para desarrollar el estudio, por lo que ésta fue cedida el tiempo necesario para la elaboración de éste, lo que permitió realizar el estudio en una situación real.

De acuerdo con los criterios establecidos y descritos, se definió la vivienda, que se presenta a continuación, la vivienda seleccionada tiene $53 \mathrm{~m}^{2} \mathrm{y}$ cuenta con los siguientes espacios:

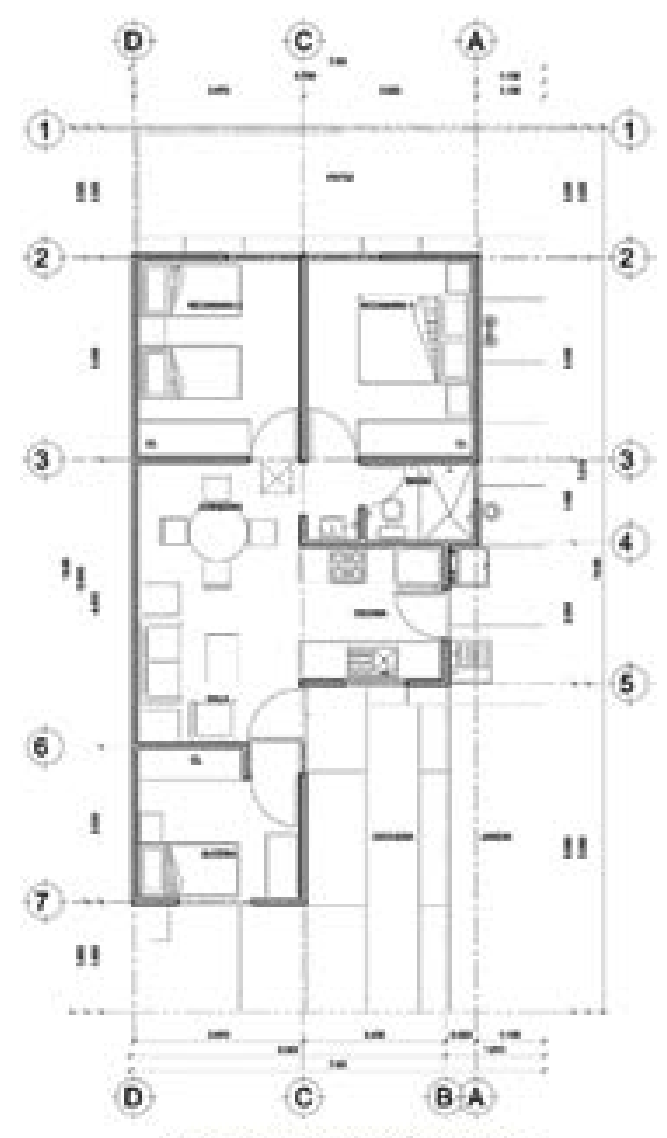

PLantra anouitectomica tso
FIGURA 2. PLANO ARQUITECTÓNICO DE LA VIVIENDA ANALIZADA. FUENTE: RUBA.

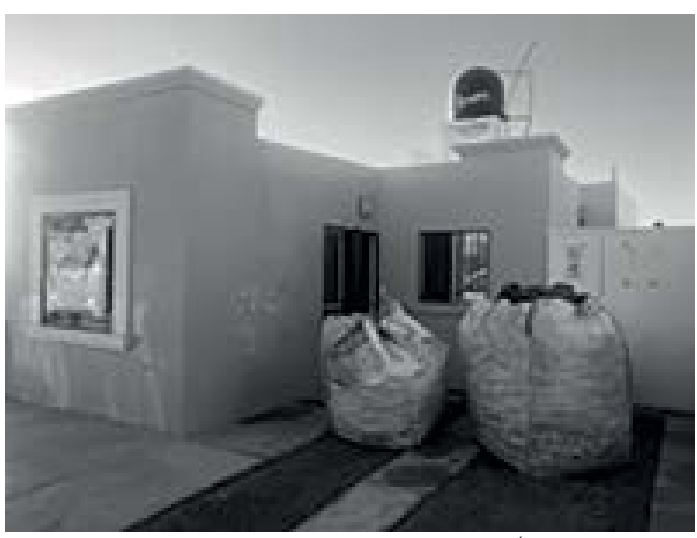

FIGURA 3. FACHADA DE LA VIVIENDA DONDE SE REALIZÓ EL ESTUDIO. FUENTE: ELABORACION PROPIA

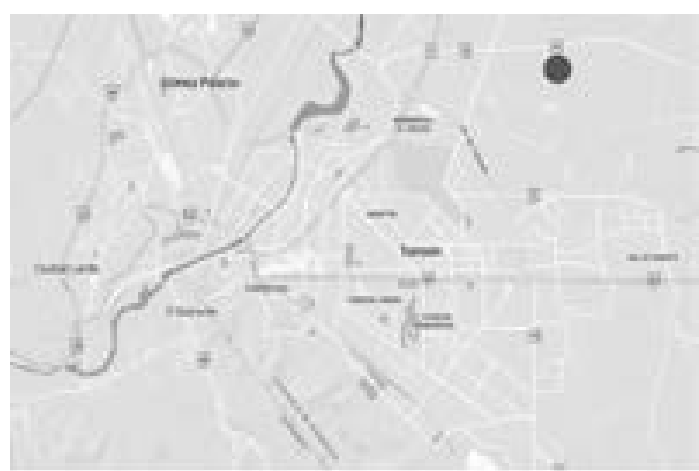

FIGURA 4. EL PUNTO ROJO MARCA LA LOCALIZACIÓN DE LA VIVIENDA DE ESTUDIO DENTRO DE LA CIUDAD DE TORREÓN, COAHUULA. FUENTE: GOOGLE MAPS (2020). 


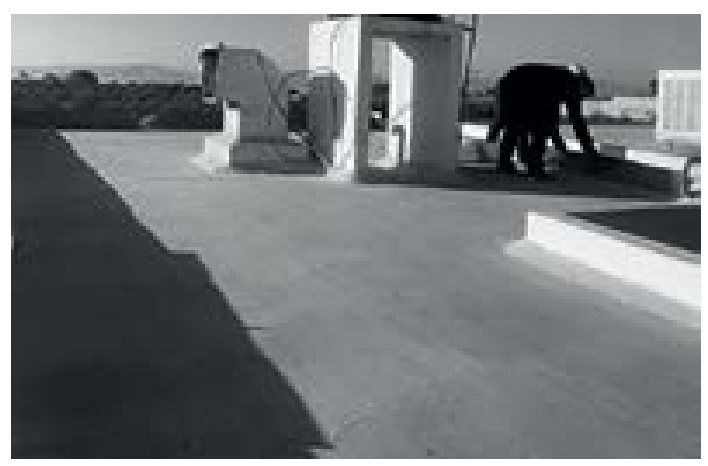

FIGURA 5. LOSA IMPERMEABILIZADA DE LA VIVIENDA ENESTUDIO. FUENTE: ELABORACIÓN PROPIA.

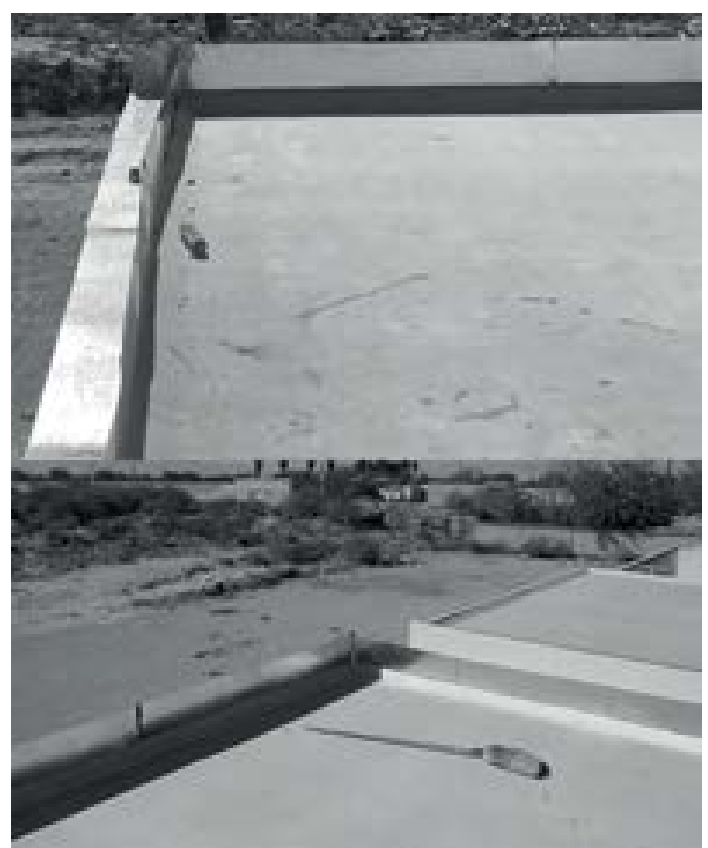

FIGURA 6. DETALLE DE INSTALACIÓN DE LA SOLERA PARA INCREMENTAR EL PRETIL Y PODER INSTALAR LA CUBIERTA VERDE. FUENTE: ELABORACIÓN PROPIA.
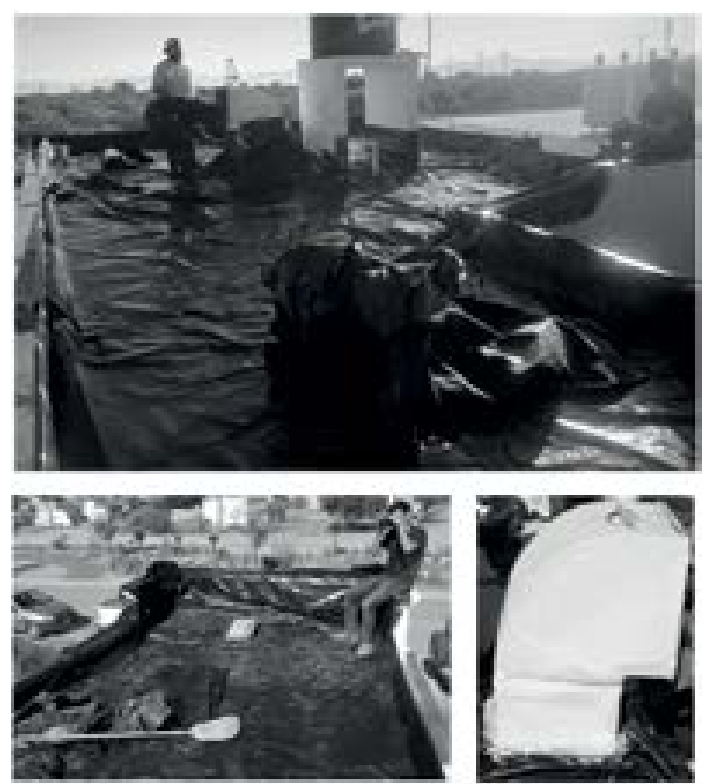

FIGURA 7. INSTALACIÓN DEL PLÁSTICO EN LA VIVIENDA SELECCIONADA IIMAGEN IZQUUERDA Y CENTRALJ. DETALLES DE IMPERMEABILIZACIÓN Y SELLADO DEL PLÁSTICO PARA EVITAR POSIBLES FILTRACIONES (IMAGEN DERECHA). FUENTE: ELABORACIÓN PROPIA.
1. Sala

2. Comedor

3. Cocina

4. 2 habitaciones

\section{Alcoba}

6. Baño

En la figura 2 se muestra la planta arquitectónica de la vivienda, así como la distribución de sus espacios. En la figura 3 se observa la fachada de la vivienda en la que se realizó el estudio. La orientación de la vivienda norte-sur, por lo que la fachada principal y el acceso que ésta da hacia el norte.

\section{LOCALIZACIÓN}

La vivienda seleccionada se localiza al noroeste de la ciudad de Torreón, Coahuila, y está en el Fraccionamiento "Veredas la Paz", Ejido la Paz, en la ciudad de Torreón, Estado de Coahuila. Dicho ejido se ubica en la zona noroeste de la ciudad (figura 4 con la localización de la vivienda dentro de la ciudad).

\section{CLIMA}

De acuerdo con la clasificación climática de Köppen, el clima en la región es BWh, que corresponde a clima árido a semiárido (Climate-Data, 2018). Según la Normales Climatológicas, las temperaturas pasan de los 30 grados desde marzo hasta septiembre, las temperaturas máximas en los meses más cálidos oscilan entre los $36^{\circ} \mathrm{C}$ hasta los $38.5^{\circ} \mathrm{C}$ (CONAGUa, 2016).

\section{CUBIERTA VERDE E INSTALACIÓN}

Sedescriben los materiales que componen la cubierta instalada y utilizada:

1. Impermeabilizante (opcional).

2. Rollo de polietileno negro calibre 600 de $6 \mathrm{~m}$ de ancho y el rollo de 80 kilos.

3. Botellas Politereftalato de Etileno (PET). 
4. Fieltro

5. Sustrato

6. Cubierta Vegetal

7. Solera para el pretil

\section{Instalación}

Se describen los diferentes pasos para la instalación de la cubierta verde en la vivienda. La pendiente mínima recomendada para instalar una cubierta verde es del $5 \%$, la cubierta de la vivienda utilizada tiene una pendiente mayor a ésta, por lo que cumple con esta recomendación.

Impermeabilizante: es necesario verificar que la superficie en donde se colocará esté impermeabilizada o que el impermeabilizante esté en buen estado, de lo contrario es necesario impermeabilizar.

Se verificó el estado del impermeabilizante y se impermeabilizaron las zonas necesarias para evitar cualquier filtración a la losa y hacia el interior de la vivienda (figura 5).

Solera Metálica: debía instalarse al final para la protección de los pretiles, fieltro y plástico, sin embargo, la vivienda analizada contaba con pretiles de $5 \mathrm{~cm}$ con chaflán, lo que dificultaba la instalación de la cubierta, por lo que la solera fue utilizada para incrementar el pretil y poder instalar adecuadamente la cubierta verde (figura 6).

Plástico: Se utilizó el plástico común y se instalaron cuatro capas de éste, cada una fue colocada en una dirección diferente con el objetivo de evitar el paso de agua y humedad, así como también proteger la losa de las raíces de la vegetación utilizada. En la figura 7 se observa la instalación del plástico en la losa.

Botellas PET: después de la instalación del plástico, se colocaron las botellas pet post uso, se recomienda limpiarlas y aplanarlas antes de instalarlas, se puede utilizar cualquier botella y se recomienda usar la misma medida para la aplicación en la losa.

Estas botellas, junto con el fieltro, cumplen la función de la malla drenante, permite un espacio adecuado entre la losa y el sustrato de tierra. En la figura 8 se observa la instalación de las botellas pet post uso en la losa de la vivienda estudiada.
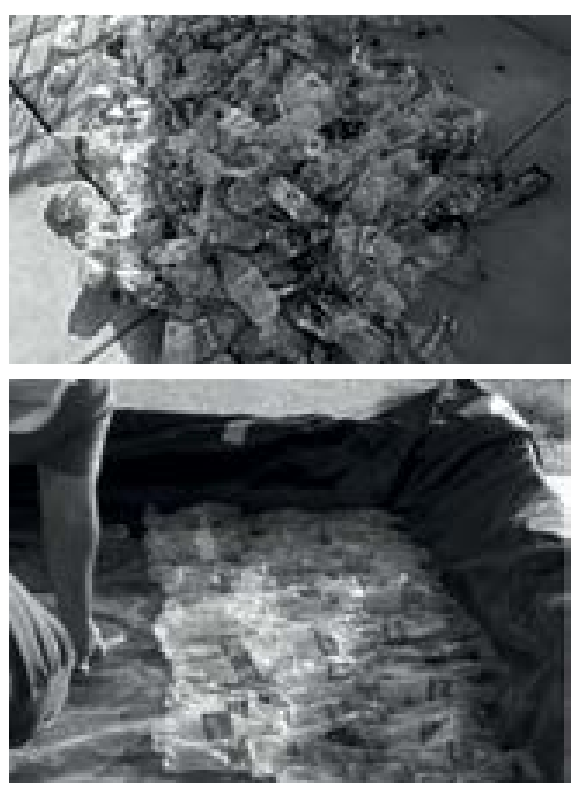

FIGURA 8. SELECCIÓN Y APLANADO DE LAS BOTELLAS PET CIMAGEN ARRIBAJ. INSTALACIÓN Y DISPOSICIÓN DE LAS BOTELLAS EN LA LOSA [IMAGEN ABAJO).

FUENTE: ELABORACIÓN PROPIA.
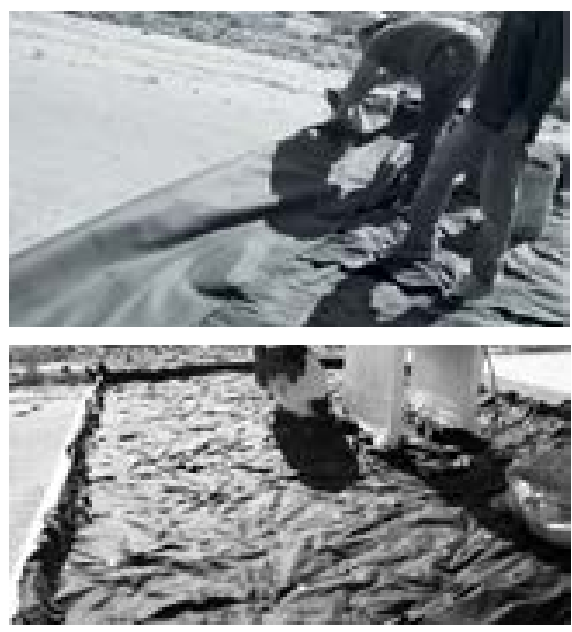

FIGURA 9. INSTALACIÓN DEL FIELTRO EN LA LOSA DE LA VIVIENDA. FUENTE: ELABORACIÓN PROPIA.
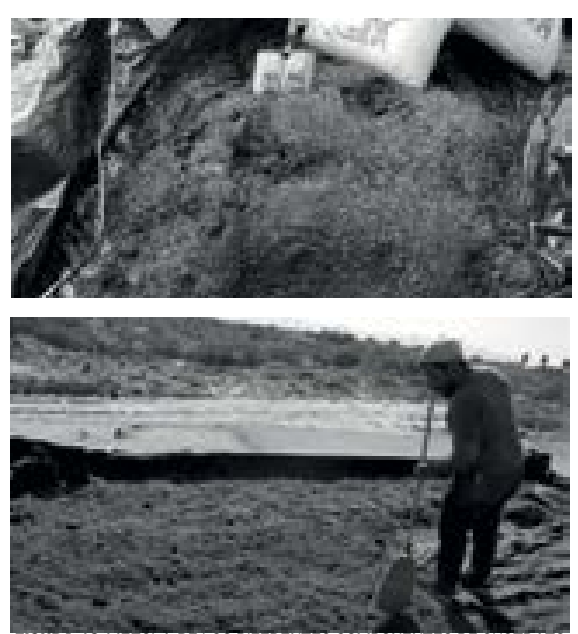

FIGURA 10.MEZCLA DE LOS DIFERENTES COMPONENTES DE SUSTRATO DE TIERRA CIMAGEN ARRIBA]. APLICACIÓN Y DISTRIBUCIÓN UNIFORME DE

ÉSTE [IMAGEN ABAJO).

FUENTE: ELABORACIÓN PROPIA. 

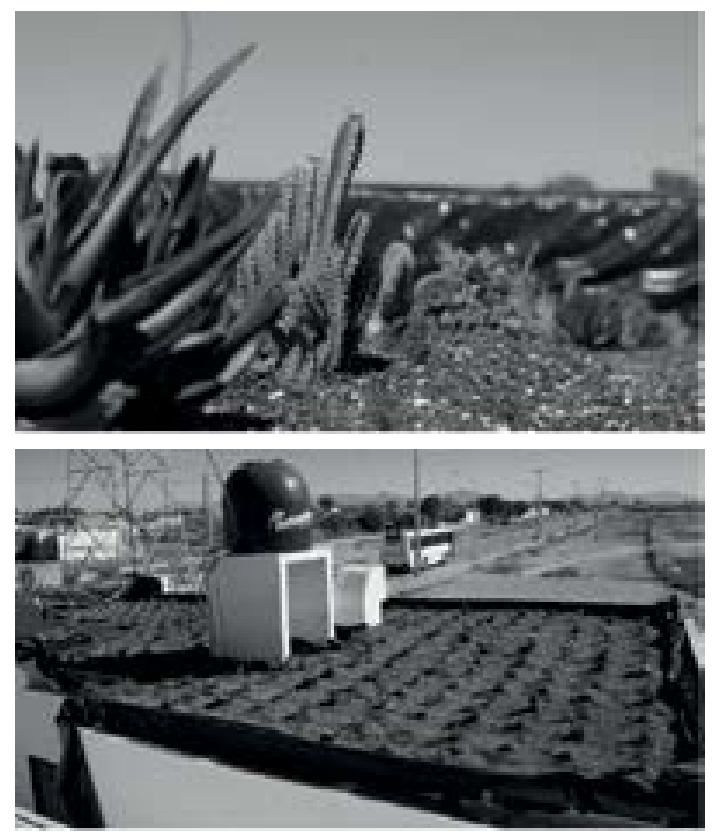

FIGURA 11. PLANTAS UTLIZZADAS EN LA CUBIERTA VERDE [IMAGEN ARRIBAJ. VISTA GENERAL DE LA CUBBERTA VERDE TERMINADA [IMAGEN ABAJO]. FUENTE: ELABORACIÓN PROPIA.

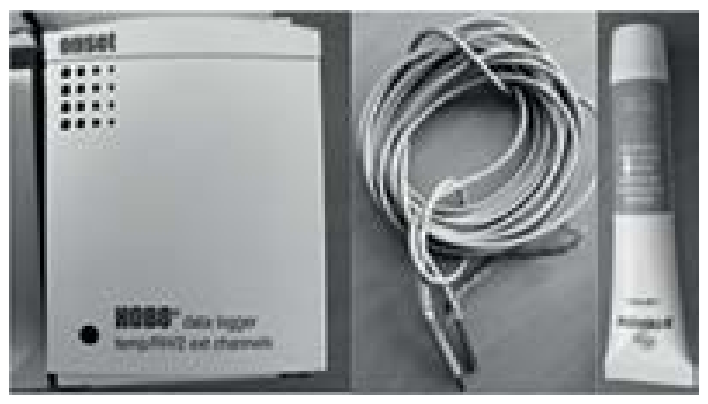

FIGURA 12. EN LA IMAGEN IZOUUERDA SE OBSERVA EL EOUIPO HoBO MODELO U12. EN LA IMAGEN CENTRAL SE VE EL TIPO DE TERMOPAR UTULIZADO QUE REGISTRÓ LAS TEMPERATURAS SUPERFICIALES INTERNAS DE LA LOSA Y MUROS Y EN LA IMAGEN DERECHA SE VE LA PASTA TÉRMICA UTLIZADA. FUENTE: ELABORACIÓN PROPIA.
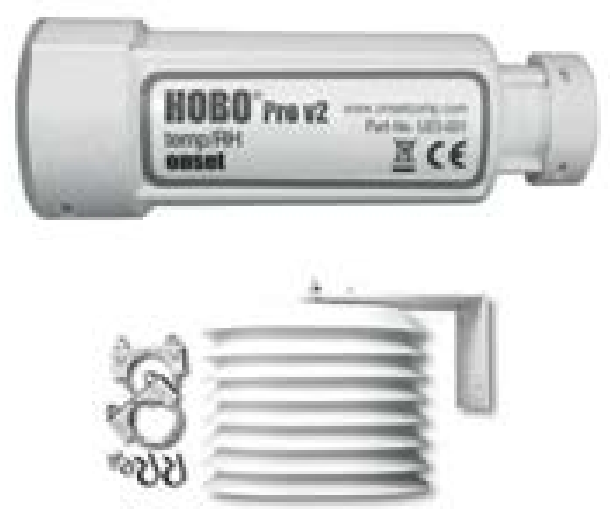

FIGURA 13. SENSOR Hobo PRO V2 DE TEMPERATURA Y HUMEEDAD EXTERNA Y PROTECTOR DE RADIACIÓN SOLAR M-RSA.

FUENTE: (HOBD, N.D.].
Fieltro: en conjunto con las botellas cumple la función de la malla drenante, el fieltro es el elemento que evita que el sustrato de tierra se deslave con el agua del riego o de la lluvia.

Se colocaron cuatro capas de fieltro, cada una de ellas se instaló en diferentes direcciones para evitar el deslave del sustrato. En la figura 9 se observa la instalación del fieltro en la losa de la vivienda.

Sustrato de Tierra: es la capa de tierra de $10 \mathrm{~cm}$ en donde será colocada la vegetación que se utilizará para la cubierta verde.

La composición del sustrato fue desarrollada en la investigación descrita previamente, este sustrato tiene la característica de ser ligero y permite su instalación en viviendas nuevas o existentes sin comprometerlas estructuralmente. A seguir se describe la composición de éste. La ventaja de la utilización de este sustrato es que el peso húmedo o saturado no sobrepasa los $50 \mathrm{~kg} / \mathrm{m}^{2}$, por lo que la utilización de éste no compromete la estructura de la vivienda ni necesita algún refuerzo o preparación adicional.

Composición (Castañeda Nolasco G., 2017): 20\% Perlita/Agrolita, 20\% fibra de coco, 20\% Humus y 40\% Peat Moss. Peso seco: $30 \mathrm{~kg} / \mathrm{m}^{2}$, Peso húmedo $50 \mathrm{~kg} / \mathrm{m}^{2}$.

En la figura 10 se observa la mezcla de los componentes del sustrato, así como la aplicación y distribución de éste en la losa de la vivienda.

Cubierta Vegetal: en el caso específico de este proyecto y de acuerdo con el clima de la región, se propuso la utilización de cactáceas, esto se debe a que además de la adaptación al clima de la región, requieren un menor consumo de agua para su mantenimiento. En la figura 11 se observan las cactáceas instaladas en la cubierta verde, las cuales quedaron a 30 cm entre cada una. 


\section{EquiPo UTILIZADO E INSTALACIÓN}

Se menciona y describen las características del equipo de mediciones utilizado durante el desarrollo del proyecto.

\section{Sensores UTILIZADOS}

Para las mediciones se empleó equipo de marca ново modelo U12-012 que registra temperatura del aire, temperatura superficial y humedad. Cada uno de los
новоS U12 utilizados midió Temperatura Interna del Aire, Temperatura Superficial de la Losa y Temperatura Superficial del Muro. En la figura 14 se puede ver el modelo de Sensor Utilizado, así como el termopar para el registro de las temperaturas superficiales.

También en la figura 12 se observa la pasta térmica utilizada, la cual sirve para asegurar de que los sensores midan la temperatura superficial y no del aire.

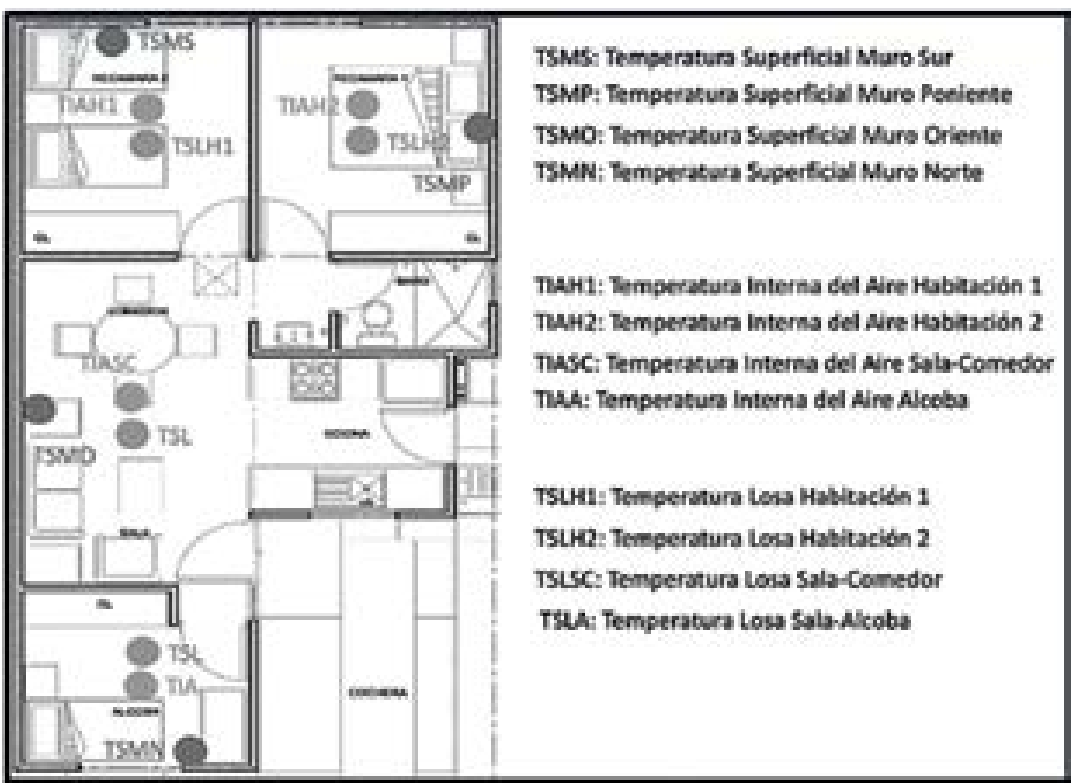

FIGURA 14. LOCALIZACIÓN DE LOS SENSORES INSTALADOS EN LOS ESPACIOS MÁS REPRESENTATIVOS DE LA VIVIENDA ESTUDIADA. FUENTE: ELABORACIÓN PROPIA CON LA PLANTA ARQUUTECTÓNICA BRINDADA POR LA EMPRESA RUBA.

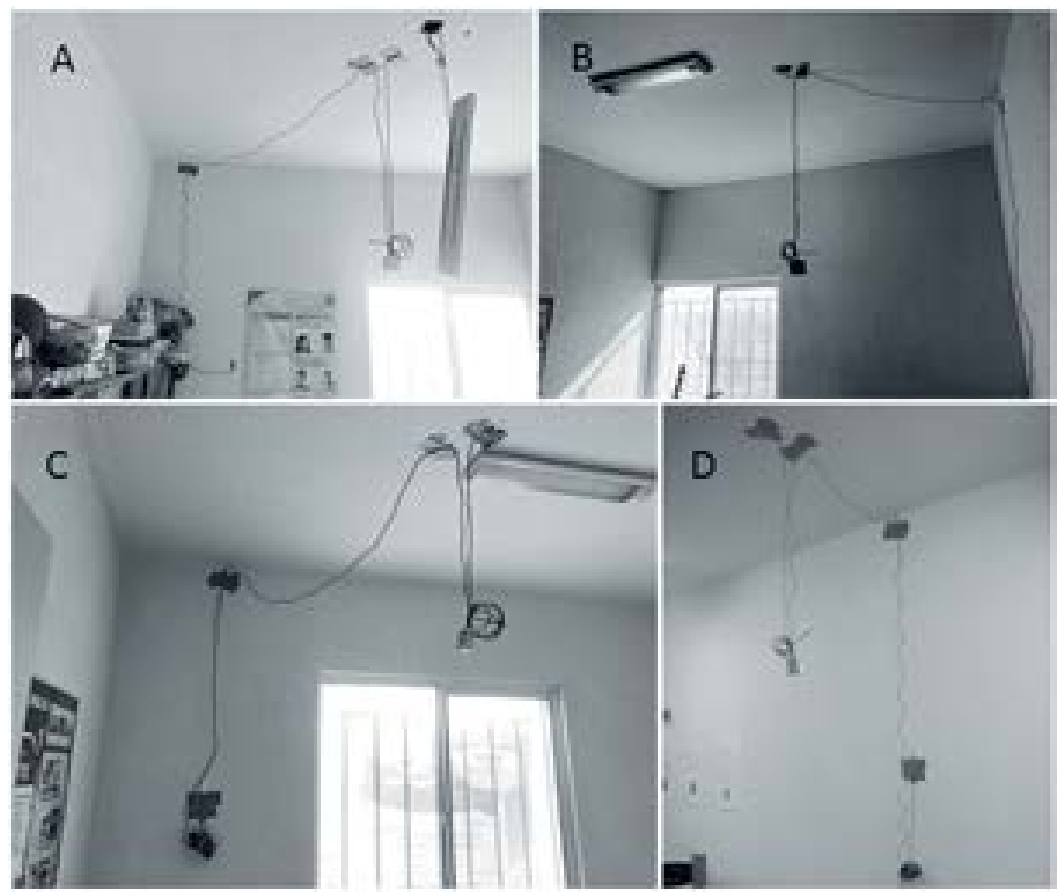

FIGURA 15. SENSORES INSTALADOS EN CADA UNO DE LOS ESPACIOS MÁS REPRESENTATIVOS DE LA VIVIENDA. A-HABITACIÓN 1, B-HABITACIÓN 2, C-ALCOBA, D-SALA/COMEDOR. FUENTE: ELABORACIÓN PROPIA. 


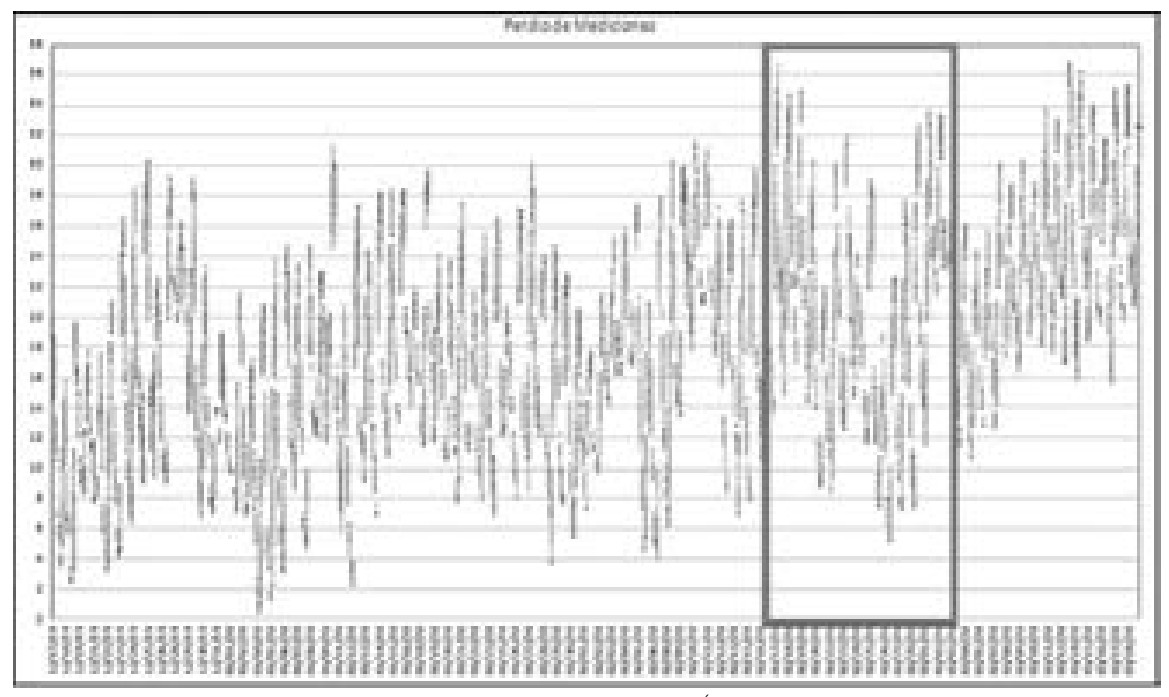

FIGURA 16. PERIODO DE MEDICIONES EXPERIMENTALES, QUE COMPRENDÓ DEL 17 DE DICIEMBRE DE 2019 AL 18 DE MARZO DE 2020

FUENTE: ELABORACIÓN PROPIA.

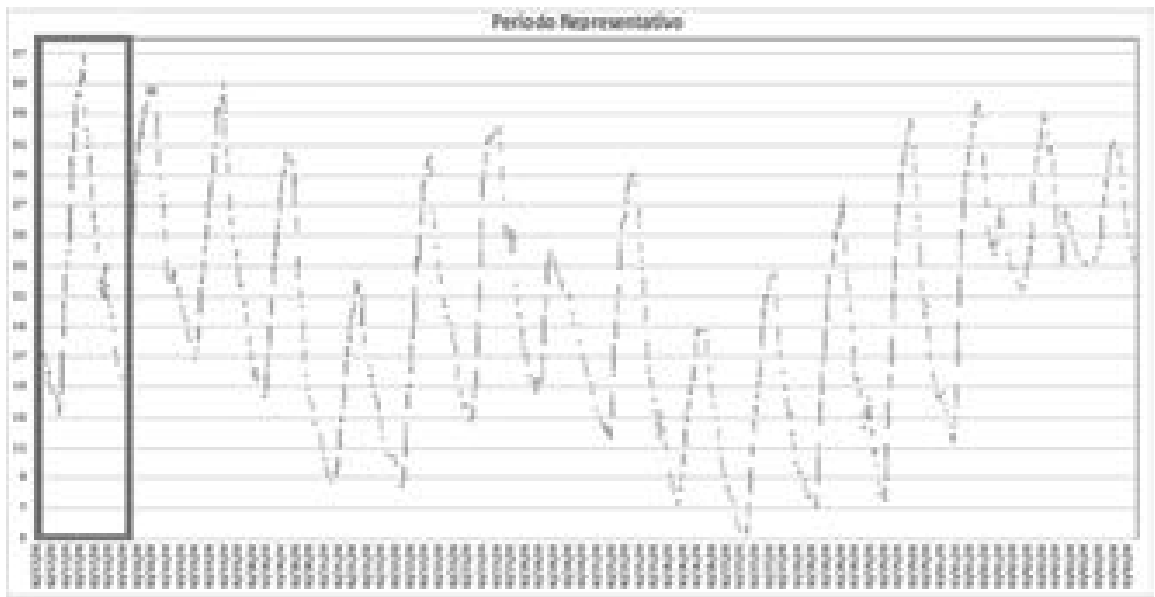

FIGURA 17. PERIODO REPRESENTATIVO TOMADO DEL PERIODO DE MEDCIONES, QUECOMPRENDE DEL 2 DE FEBRERO DE 2020 AL 3 DE MARZO DE 2020.

FUENTE: ELABORACIÓN PROPIA.

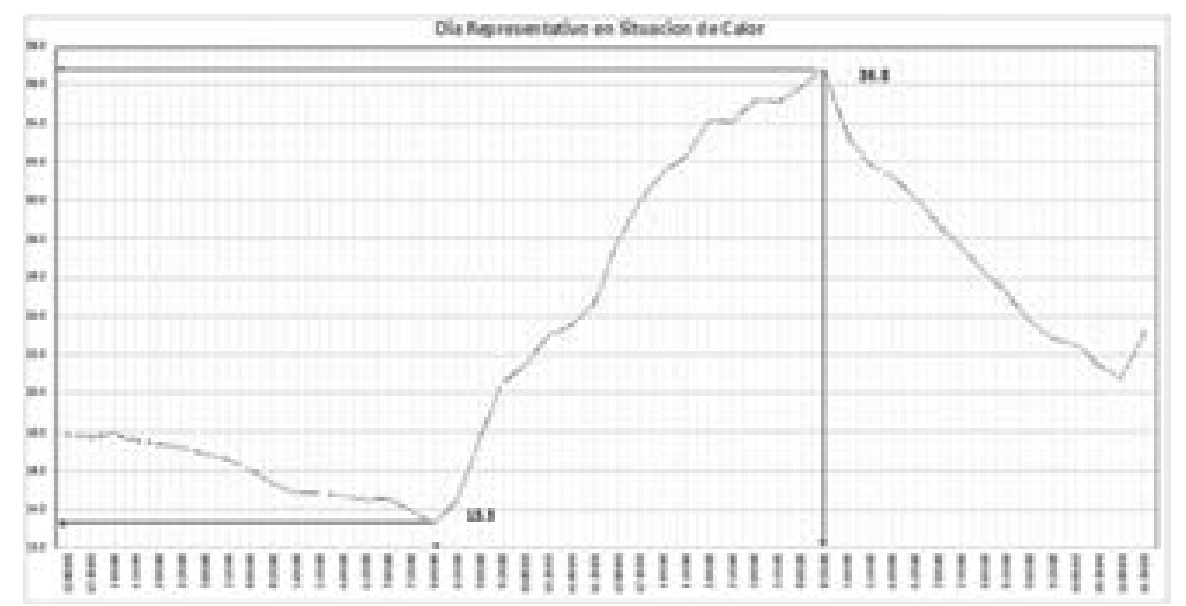

FIGURA 18. DÍA REPRESENTATIVO EN UNA SITUACIÓN DE CALOR. ESTE DíA SE TOMÓ DEL EPISODIO REPRESENTATIVO, EL CUAL FUE EL MÁS CÁLIDO Y SE PRESENTÓEL 17 DE FEBRERO DE २०२०.

FUENTE: ELABORACIÓN PROPIA. 


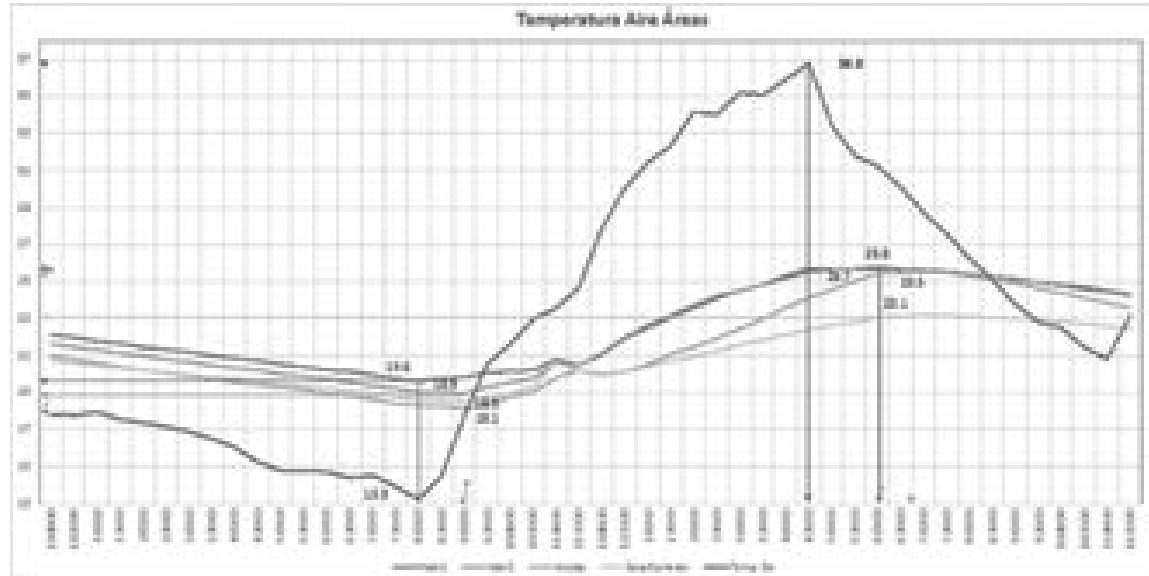

FIGURA 19. GRÁFICO CON LOS RESULTADOS DE TODAS LAS TEMPERATURAS INTERNAS DEL AIRE DE LAS DIFERENTES ZONAS QUE COMPONEN LA VIVIENDA ESTUDIADA.

FUENTE: ELABORACIÓN PROPIA.

Para medir la temperatura del aire externa se utilizó el sensor ново PRO V2, que registra temperatura y humedad, para proteger al sensor se utilizó un protector de radiación solar modelo M-RSA (figura 13).

\section{INSTALACIÓN Y LOCALIZACIÓN DE LOS SENSORES}

En cada uno de los espacios representativos de la vivienda se midió la temperatura del aire, la temperatura superficial de la losa y la temperatura del muro que daba hacia la parte exterior (quedando en norte, sur, oriente $\mathrm{y}$ poniente).

En la figura 14 se ve la localización de los sensores instalados en los diferentes espacios de la vivienda. En esta imagen también se marca la simbología de cada uno de los sensores que se midió específicamente.

En la figura 15 se ven los sensores instalados en cada uno de los espacios, para medir la temperatura del aire, temperatura superficial de la losa y temperatura superficial del muro.

\section{Métodos de Análisis}

El método es el propuesto por Vecchia (1997), replicado por Quiroa Herrera, J. A.; Vecchia, F.; Castañeda Nolasco (2010) y Trujillo Samayoa et al. (2015), en el cual se utiliza a la climatología dinámica y sus estados de tiempo para el análisis en ambientes construidos.

Basados en el método de Vechia (1997), para el análisis se utilizará la climatología dinámica, dentro de la cual se definirá lo que se describe a continuación.
Periodo Experimental: es el periodo en el que se realizarán las mediciones.

Episodio Representativo: es el periodo en el que se buscará identificar la interacción de las masas de aire fría y cálida en la región de estudio, en donde pueda identificarse la fase de calentamiento prefrontal, el cual se presenta al inicio del periodo representativo seleccionado.

Día Representativo: día seleccionado de acuerdo con los datos y con los cuales se hará el análisis comparativo. El día seleccionado será en una situación de calor seleccionado del episodio representativo y en la fase de calentamiento prefrontal.

\section{Resultados y Discusiones Periodo de Mediciones}

En la figura 16 se observa el periodo de mediciones para el experimento realizado. Dicho periodo está comprendido del 17 de diciembre de 2019 al 18 de marzo de 2020, por lo que comprende tres meses de mediciones.

En el gráfico se ven claramente las interacciones de las masas 


\begin{tabular}{|c|c|c|c|c|c|c|}
\hline Datos & Máxima & Minima & $\begin{array}{l}\text { Menor Amplit } \\
\text { Térmica }\end{array}$ & $\begin{array}{l}\text { Mayor } \\
\text { Amplifud } \\
\text { Termica }\end{array}$ & $\begin{array}{l}\text { Mayor Atras } \\
\text { Ttermico }\end{array}$ & $\begin{array}{l}\text { Menor } \\
\text { Atraso } \\
\text { Térmico }\end{array}$ \\
\hline Registros & $\begin{array}{l}\mathrm{Hab}-2 \\
\left(25.8^{\circ} \mathrm{C}\right)\end{array}$ & $\begin{array}{l}\text { SalayComedor } \\
\left(23.1^{\circ} \mathrm{C}\right)\end{array}$ & $\begin{array}{l}\text { Sala/Comedor } \\
\left(8.5^{*} \mathrm{C}\right)\end{array}$ & $\begin{array}{l}\text { Alcoba } \\
\left(13.7^{\circ} \mathrm{C}\right)\end{array}$ & $\begin{array}{l}\text { Sala/Comedor } \\
\text { Alcoba } \\
\text { (2:00 hrs) }\end{array}$ & $\begin{array}{l}\text { Hab-1 } \\
\text { Hab-2 } \\
(1: 30 \text { hrs })\end{array}$ \\
\hline Diferencias & $27^{\circ} \mathrm{C}$ & & $5.2^{\circ} \mathrm{C}$ & & 30 minutos & \\
\hline
\end{tabular}

de aire durante el periodo, así como las variaciones de las temperaturas en el mismo. En el recuadro rojo, se marca al que se identifica como al episodio representativo.

\section{EPISODIO REPRESENTATIVO}

Para la definición del episodio representativo, se buscó en el que fuera evidente la interacción de masas de aire y en el cual se pudiera identificar plenamente el fenómeno conocido como calentamiento prefrontal, este fenómeno se caracteriza como su nombre lo indica, a una elevación de temperaturas en la fase previa a la entrada de una masa de aire frío, en éste se presentan varios días en los cuales las temperaturas son elevadas.

Como se observa en la figura 17, el episodio está comprendido

FUENTE: ELABORACIÓN PROPIA.

del 17 de febrero al 03 de marzo de 2020. De los días 17 al 19 es en donde se puede identificar el fenómeno del calentamiento prefrontal. En el recuadro rojo se marca el día seleccionado como día representativo.

\section{Día Representativo de MáXimo calor}

Una vez identificando el episodio representativo, se procede a identificar el día representativo, que en este caso fue el 17 de febrero de 2020, dicho día fue seleccionado, ya que fue el más cálido del episodio analizado.

En la figura 18 puede observarse el día representativo seleccionado. La temperatura del aire mínima en este día fue de $13.3^{\circ} \mathrm{C}$ registrado a las 8:0o horas, la temperatura máxima fue de $36.8^{\circ} \mathrm{C}$ registrada a las 16:30 hrs. La amplitud térmica presentada entre éstas es de $23.5{ }^{\circ} \mathrm{C}$.

\section{Tenperaturas Aire}

A seguir los valores de temperatura registrados en las temperaturas del aire internas de los diferentes espacios medidos en la vivienda en

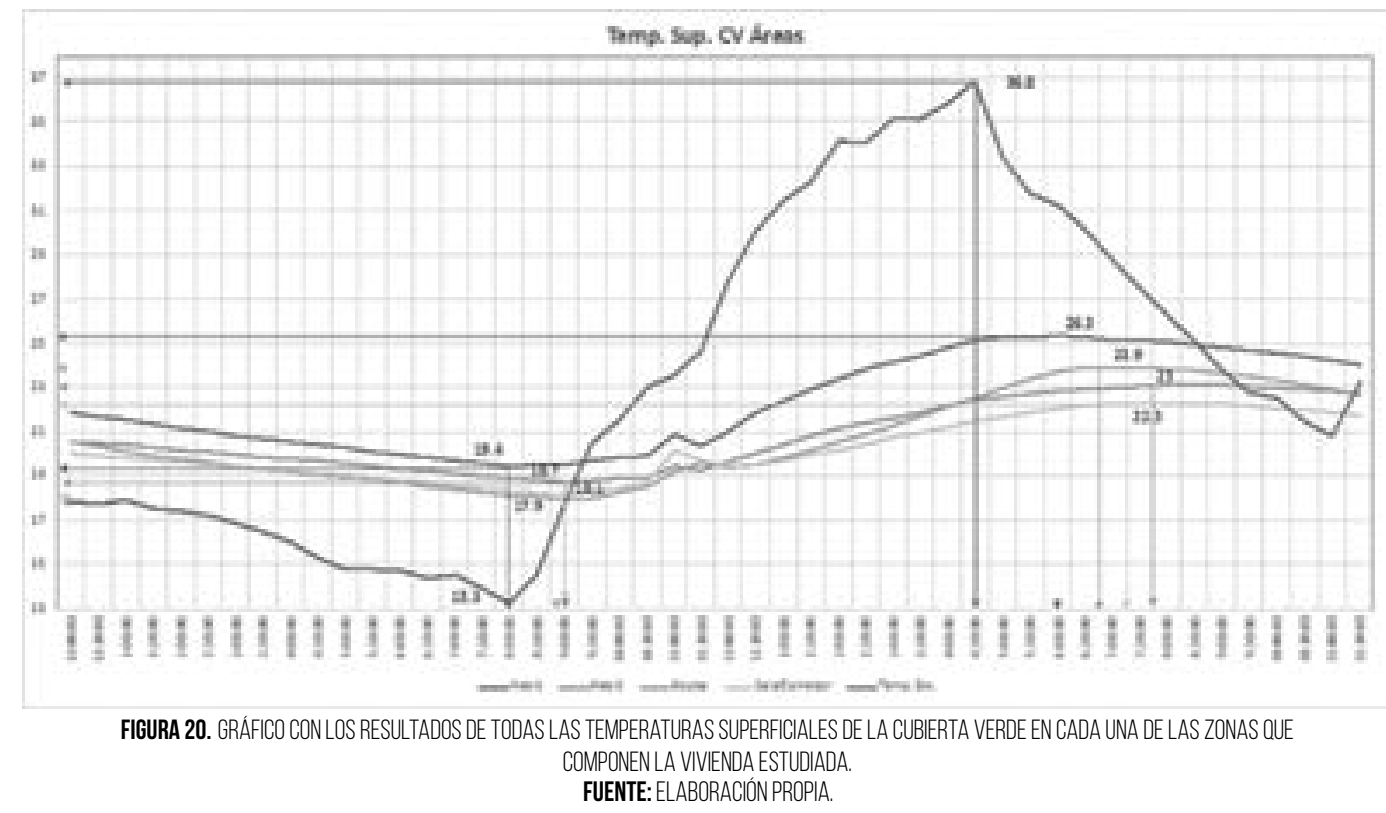




\begin{tabular}{|c|c|c|c|c|c|c|}
\hline Datos & Máxima & Minima & $\begin{array}{l}\text { Menor } \\
\text { Amplitud } \\
\text { Térmica }\end{array}$ & $\begin{array}{l}\text { Mayor } \\
\text { Amplitud } \\
\text { Térmica }\end{array}$ & $\begin{array}{l}\text { Mayor } \\
\text { Atraso } \\
\text { Térmico }\end{array}$ & $\begin{array}{l}\text { Menor Atraso } \\
\text { Térmico }\end{array}$ \\
\hline Registros & $\begin{array}{l}\text { Hab-1 } \\
\left(26.3^{\circ} \mathrm{C}\right)\end{array}$ & $\begin{array}{l}\text { Sala/Comedor } \\
\left(22.3^{\circ} \mathrm{C}\right)\end{array}$ & $\begin{array}{l}\text { rSala/Comedor } \\
\left(4.2^{\circ} \mathrm{C}\right)\end{array}$ & $\begin{array}{l}\text { Alcoba } \\
\left(6.9^{\circ} \mathrm{C}\right)\end{array}$ & $\begin{array}{l}\text { Hab-2 (3:00 } \\
\text { hrs) }\end{array}$ & $\begin{array}{l}\text { (1:30 hrs) }\end{array}$ \\
\hline Diferencias & $4^{\circ} \mathrm{C}$ & & $2.7^{\circ} \mathrm{C}$ & & $1: 30$ hrs & \\
\hline
\end{tabular}

estudio. En la figura 19 se puede observar e identificar lo siguiente:

1. Ninguna de las temperaturas máximas fue mayor que la temperatura máxima externa del aire.

2. Ninguna de las temperaturas mínimas fue menor que la temperatura mínima externa del aire.

3. Las diferencias de las temperaturas internas a las externas fueron mayores a $10^{\circ} \mathrm{C}$ en todos los casos, siendo la Habitación 2 la que mostró la temperatura más elevada.

4. La que presentó los valores máximos y mínimos de temperatura, así como la mayor amplitud térmica fue la Alcoba.

5. Las áreas de Habitación 1 y 2 presentaron un comportamiento casi idéntico en el transcurso del día, en la Alcoba, aunque presentó alguna diferencia también es muy similar a los espacios anteriores.

6. El área Sala-Cocina fue la que tuvo la temperatura más baja en el transcurso del día. Como se ve en el gráfico, también es el área que presentó mayores diferencias en el transcurso del día evaluado.

7. Todas las áreas presentaron atraso térmico en las temperaturas máximas y en las mínimas.

En la tabla 1 se muestra la síntesis de las diferencias entre las mediciones realizadas en las diferentes áreas de la vivienda analizada, donde se indica cuál de las temperaturas presentaron mayores o menores valores, así como amplitud térmica y horarios.

En el rubro de las temperaturas internas del aire, aunque sí se presentan diferencias entre los diferentes espacios analizados, éstas no fueron significativas y en general mantuvieron un compotamiento similar. Las diferencias están relacionadas a las dimensiones y características de los espacios, es por eso que los espacios idénticos, como lo son las Habitaciones, no tuvieron prácticamente ninguna diferencia entre sí a lo largo del día.

Todas las áreas presentaron diferencia significativa comparada con la temperatura del aire exterior, lo que significa que además de un comportamiento adecuado, se están mitigando las condiciones climáticas externas en el día evaluado.

\section{Temperaturas Superficiales Cubierta}

En esta sección se presentan los datos de las temperaturas superficiales de la cubierta verde en los diferentes espacios que fueron medidos experimentalmente en la vivienda evaluada. En la figura 20 se puede observar e identificar lo siguiente:

Ninguna de las temperaturas máximas fue mayor que la temperatura máxima externa del aire.

1. Ninguna de las temperaturas mínimas fue menor que la temperatura mínima externa del aire.

2. Las diferencias de las temperaturas internas a las externas fueron mayores a $10^{\circ} \mathrm{C}$ en todos los casos, siendo la Habitación 1 la que presentó la temperatura más elevada. 


\begin{tabular}{|c|c|c|c|c|c|c|}
\hline Datos & Máxima & Minima & $\begin{array}{l}\text { Menor } \\
\text { Amplitud } \\
\text { Termica }\end{array}$ & $\begin{array}{l}\text { Mayor } \\
\text { Amplitud } \\
\text { Termica }\end{array}$ & $\begin{array}{l}\text { Mayor } \\
\text { Atraso } \\
\text { Térmico }\end{array}$ & $\begin{array}{l}\text { Menor Atraso } \\
\text { Térmico }\end{array}$ \\
\hline Registros & $\begin{array}{l}\mathrm{Hab}-2 \\
\left(28.9^{\circ} \mathrm{C}\right)\end{array}$ & $\begin{array}{l}\text { Sala/Comedor } \\
\left(24.1^{\circ} \mathrm{C}\right)\end{array}$ & $\begin{array}{l}\text { rSala/Comedor } \\
\left(6.6^{\circ} \mathrm{C}\right)\end{array}$ & $\begin{array}{l}\mathrm{Hab}-2 \\
\left(11.2^{9} \mathrm{C}\right)\end{array}$ & $\begin{array}{l}\text { Alcoba }(2: 00 \\
\text { hrs) }\end{array}$ & $\begin{array}{l}\mathrm{Hab}-1 \\
(1: 00 \mathrm{~h})\end{array}$ \\
\hline Diferencias & $4.8^{\circ} \mathrm{C}$ & & $4.6^{\circ} \mathrm{C}$ & & $1: 00 \mathrm{~h}$ & \\
\hline
\end{tabular}

FUENTE: ELABORACIÓN PROPIA.

3. La que presentó los valores máximos y mínimos de temperatura, así como la mayor amplitud térmica fue la Habitación 1. Esta fue el área que mostró mayores diferencias con relación a las demás.

4. Las áreas de Habitación 1, Alcoba y Sala/Comedor presentaron un comportamiento similar entre estas.

5. El área Sala-Cocina fue la que tuvo la temperatura más baja en el transcurso del día.

6. Todas las áreas presentaron atraso térmico en las temperaturas máximas y en las mínimas.

En la tabla 2 se presenta la síntesis de las diferencias entre las mediciones realizadas en las diferentes áreas de la vivienda analizada en donde se indica cuál de las temperaturas presentaron mayores o menores valores, así como amplitud térmica y horarios.

En las temperaturas superficiales de la cubierta verde, se presentan diferencias entre los diferentes espacios analizados, estas no superaron los $4{ }^{\circ} \mathrm{C}$, a pesar de esto, mantuvieron un comportamiento similar en todos los espacios. La Habitación 2 presentó más diferencias con relación a los demás espacios.

Todas las áreas mostraron una diferencia significativa comparada con la temperatura del aire exterior, en este caso, la superficial que está más expuesta a la radiación solar es la cubierta, sin embargo, la cubierta verde además de presentar un comportamiento térmico adecuado, la cual, está mitigando las condiciones climáticas externas en el día evaluado, entre éstas la incidencia de la radiación solar, así como de la temperatura externa.

\section{Temperaturas Superficiales Muros}

A seguir, se presentan los datos de las temperaturas superficiales de los muros, registradas en los diferentes espacios que fueron medidos experimentalmente en la vivienda. En la figura 21 se puede observar e identificar lo siguiente:

1. Ninguna de las temperaturas máximas fue mayor que la temperatura máxima externa del aire, sin embargo, las diferencias fueron menores en comparación a las demás mediciones.

2. Ninguna de las temperaturas mínimas fue menor a la temperatura mínima externa del aire.

3. Las diferencias de las temperaturas internas a las externas fueron mayores a $7.9{ }^{\circ} \mathrm{C}$ en todos los casos, siendo la Habitación 2 la que presentó la temperatura más elevada.

4. La que presentó los valores máximos y mínimos de temperatura, así como la mayor amplitud térmica fue la Habitación 2. Esta fue el área que presentó mayores diferencias con relación a las demás.

5. Las áreas de Habitación 1 y Alcoba presentaron un comportamiento similar entre éstas.

6.El área Sala-Cocina fue la que tuvo la temperatura más baja en el transcurso del día. 
7. Todas las áreas presentaron atraso térmico en las temperaturas máximas y en las mínimas.

8. Las temperaturas superficiales de los muros fueron mayores que las temperaturas internas del aire, así como de las temperaturas superficiales de la cubierta verde.

9. Laorientación más comprometidafue hacia el sur y la menos comprometida fue el oriente. Las orientaciones norte y poniente tuvieron un comportamiento similar.

En la tabla 3 se presenta la síntesis de las diferencias entre las mediciones realizadas en las diferentes áreas de la vivienda analizada. En esta se indica cuál de las temperaturas presentaron mayores o menores valores, así como amplitud térmica y horarios.

En las temperaturas superficiales de los muros en sus diferentes orientaciones (norte, sur, esteyoeste), las cuales llegaron a $4.8^{\circ} \mathrm{C}$. El comportamiento en cada uno de los espacios fue diferente, aunque en dos espacios se presentaron similitudes, tal es el caso de la Habitación 1 (poniente) y Alcoba (norte), ambos quedaron en un rango intermedio con relación a los otros dos espacios. La Habitación 2 (sur) registró la temperatura más elevada y la Sala/Comedor tuvo menores valores.

Lo anterior muestra la orientación de los muros tiene una influencia importante en la ganancia térmica, siendo el muro sur el más comprometido (esto debido a la trayectoria solar en la región) y el muro oriente el menos comprometido en el caso analizado.

Todas las áreas presentaron una diferencia significativa comparada con la temperatura del aire exterior, sin embargo, fue en los muros que se registraron las mayores temperaturas en el proceso de evaluación de la vivienda, superando a las temperaturas del aire y de la cubierta verde.

\section{CONCLUSIONES}

El comportamiento de la vivienda con la cubierta verde ligera fue positivo en todos los casos o espacios analizados, en todos los casos las temperaturas internas del aire y superficiales fueron significativamente menores que la temperatura externa, aunque se presentaron diferencias entre estos espacios, las cuales no fueron tan significativas, pero sí más evidentes en algunos casos.

La vivienda en su conjunto tuvo buen comportamiento térmico con relación a la temperatura del aire externa en la situación de calor analizada, las diferencias de las temperaturas llegó a superar los $10{ }^{\circ} \mathrm{C}$ en la mayoría de los casos. Esta diferencia ya puede ser significativamente perceptible para los usuarios de las viviendas.

En todos los casos las temperaturas superficiales de la cubierta verde ligera registraron menores valores que las temperaturas superficiales de los muros, siendo que la cubierta es la parte del edificio que está expuesta a los efectos de la radiación solar, esto significa que disminuyó significativamente la ganancia térmica por la losa.

Por lo anterior, menores valores de temperaturas internas pueden significar un ahorro en el rubro energético, por la disminución o no utilización de sistemas activos como los son los aires lavados, ventiladores y aires acondicionados etc., por lo que esto también representaría ahorro económico también.

En las temperaturas superficiales de los muros también se presentaron diferencias, evidenciando al muro sur como el más comprometido y al muro oriente como el menos comprometido, en caso de los muros norte y poniente, presentaron un comportamiento similar.

Las temperaturas internas de aire presentaron valores menores a la temperatura externa y en todos los casos también fueron menores a los valores de las temperaturas superficiales 
de los muros, lo que muestra cómo la cubierta verde también disminuyó considerablemente la ganancia térmica al interior de la vivienda reflejándose en menores valores de temperatura.

La cubierta verde ligera estudiada es una tecnología, que además de mejorar considerablemente el comportamiento térmico de la vivienda, también funciona como una estrategia de mitigación para el clima de la región, haciendo que la vivienda esté mejor adaptada y que tenga una mejor respuesta a las variaciones y excitaciones climáticas, por lo que la cubierta verde podría valorarse como una opción de ecotecnología a tomarse en cuenta por el INFONAVIT (2018).

También con su utilización se estaría atendiendo lo indicado en el Plan Estatal de Desarrollo 2017-2023 en el eje 3 "Desarrollo Económico Sustentable", en el punto 3.9 en donde menciona, entre otras cosas, que se ofrezca vivienda para una vida digna. En el eje 4 "Desarrollo Social Incluyente", en el que se busca uno de los aspectos es el mejoramiento de la vivienda (Gobierno del Estado de Coahuila de Zaragoza, 2017).

Por lo anterior, mayores beneficiarios al aplicarse y utilizarse serían son los usuarios de estas viviendas, mejorando el ambiente el ambiente interno de la vivienda de interés social, lo que se traduce a una mejora del ambiente interno, así como a una mejora la calidad de vida de los usuarios de ésta. Por lo que de acuerdo con las características de la cubierta verde utilizada como el no requerir un refuerzo estructura y en donde sus componentes se encuentren en la región, esto facilita su implementación y por ende los beneficios que esto conlleva al grupo social que lo utilice.
Además de que esta tecnología represente una estrategia de mitigación al mejorar el ambiente térmico interno, esto significaría una disminución del consumo energético y de esta forma disminución de emisión de gases de efecto invernadero, mejorando la capacidad de la vivienda a las variaciones climáticas de la región, además de los impactos positivos que esto conlleve.

\section{RECOMENDACIONES}

Investigar e identificar opciones alternativas de sustrato ligero que pueda ser utilizadas en la cubierta verde, esto permitirá tener otras posibilidades, lo que facilitaría su implementación.

Los objetivos y alcances planteados en la presente investigación fueron hechos de acuerdo con el tiempo y recursos disponibles, sin embargo, lo ideal es continuar el estudio para conocer los beneficios de la cubierta en corto, mediano y largo plazo.

\section{AGRADECIMIENTOS}

Al Consejo Estatal de Ciencia y Tecnología del Estado de Coahuila (СОАсут), por el apoyo otorgado al proyecto FONCYTCOECYT-COAH-2O19-C13-CO84.

Al InFONAVit, por el apoyo y las facilidades otorgadas para la realización del proyecto de investigación.

A la empresa RUBA, por facilitar una de las viviendas que producen en la región para poder realizar el estudio.

$\mathrm{Al}$ Sistema Nacional de Investigadores (sNi) del Consejo Nacional de Ciencia y Tecnología (CONACYT) por la beca otorgada. 


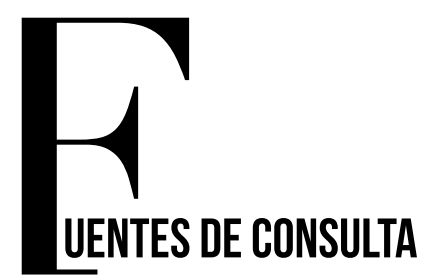

Castañeda Nolasco G. (2017), Adaptación de techo verde aplicable a la vivienda de interés social (Informe Técnico inédito, PINCC-UNAM). Facultad de Arquitectura, Universidad Autónoma de Chiapas.

Climate-Data (2018), Clima Torreón. Disponible en http:// es.climate-data.org/location/872606/, consultado el 5 de septiembre de 2020.

Comisión Nacional de Vivienda (CONAVI) (2014), Guía de Orientación para atender vivienda en los municipios. 86. Disponible en http:// www.conavi.gob.mx:8080/Otros/Docs/GUIA ORIENTACION 3.o Enero 2014.pdf, consultado el 10 de septiembre de 2020.

Cook, L. M. \& Larsen, T. A. (2021), "Towards a performance-based approach for multifunctional green roofs: An interdisciplinary review",Building andEnvironment, 188(September 2020), 107489. Disponible en https://doi.org/10.1016/j.buildenv.2020.107489, consultado el 5 de septiembre de 2020.

Díaz Duarte, S. C., González Escobar, D., Borja Ruíz, M. F. \& Puga Navarrete, D. V. (2021), Actualización del Rezago habitacional; Censo de Población y Vivienda 2020. Disponible en https:// sniiv.conavi.gob.mx/doc/analisis/2020/Calculo_Rezago_ Habitacional_2020.pdf, consultado el 5 de agosto de 2020

Diario Oficial de la Federación (DOF) (2014), Programa Nacional de Vivienda 2014-2018. Diario Oficial de la Federación, 31. Disponible en http://www.dof.gob.mx/nota_detalle.php?codigo $=5342865 \& \mathrm{fe}$ cha $=30 / 04 / 2014$, consultado el 25 de agosto de 2020 .

Gobierno del Estado de Coahuila de Zaragoza (2017), Plan Estata de Desarrollo 2017-2023. Disponible en https://coahuila.gob. $\mathrm{mx} /$ archivos/pdf/Publicaciones/PED2017-2023/Plan_Estatal Desarrollo_baja.pdf, consultado el 10 de septiembre de 2020.

ново (n.d.). Onset ново and InTemp Data Loggers. Retrieved December 12, 2018, from http://www.onsetcomp.com/, consultado el 12 de diciembre de 2018.

Instituto del Fondo Nacional de la Vivienda (Infonavit) (2018), Hipoteca Verde. Infonavit. Disponible en http://portal.infonavit. org.mx/wps/wcm/connect/infonavit/trabajadores/cuido_mi_ casa/hipoteca+verde, consultado el 10 de septiembre de 2020.

Instituto del Fondo Nacional de la Vivienda (Infonavit) (2013), SINTESIS INFONAVIT NACIONAL. 11. Disponible en https:// portal.infonavit.org. $\mathrm{mx} / \mathrm{wps} / \mathrm{wcm} /$ connect/bo199142-doeb495f-9d8d-ce614d603968/Síntesis+-+o8+de+mayo_2013. pdf?MOD=AJJPERES\&CONVERT_TO=URL\&CACHEID=b0199142-doeb-495f9d8d-ce614d603968, consultado el 25 de agosto de 2020.

Intergovernmental Panel on Climate Change (IPCC) (2001), Anexo B. Glosario de términos. Informe de Síntesis-Cambio Climático 2001, 27. Disponible en https://www.ipcc.ch/pdf/glossary/tar-ipccterms-sp.pdf, consultado el 25 de septiembre de 2020.

Intergovernmental Panel on Climate Change (IPCC) (2019), Informe especial sobre los impactos de un calentamiento global de $1,5^{\circ} \mathrm{C}$ y las sendas de emisión relacionadas. español. In Intergovernmental Panel on Climate Change. Disponible en https://www.ipcc.ch/ sr15/, consultado el 10 de septiembre de 2020.
Jim, C. Y. (2014), "Air-conditioning energy consumption due to green roofs with different building thermal insulation", Applied Energy, 128, pp. 49-59. Disponible en https://doi.org/10.1016/j. apenergy.2014.04.055, consultado el 25 de agosto de 2020.

Quiroa Herrera, J. A., Vecchia, F., Castañeda Nolasco, G. (2010), Comparación del comportamiento térmico de tres cubiertas: láminas de reciclado tetra pak $₫$, láminas de fibrocemento y teja de barro Thermal behavior comparison of three different rooftiles : tetra pak $@$ recycled tiles , fiber-cement tiles , and ceramic. 1, 2331. Disponible en http://www.redalyc.org/pdf/467/46713348003. pdf, consultado el 5 de septiembre de 2020.

Quiroa Herrera, J. A., Castañeda Nolasco, G. \& Villanueva Solis, J. (2020), La cubierta verde como estrategia de mitigación en vivienda social ante el cambio climático ( pp. 85-113). Editorial Unión de Investigadores para la Sustentabilidad. Disponible en https://doi.org/https://doi.org/10.47386/20203007BA4, consultado el 3 de septiembre de 2020.

Razzaghmanesh, M., Beecham, S. \& Brien, C. J. (2014) "Developing resilient green roofs in a dry climate", Science of the Total Environment, 490, 579-589. Disponible en https://doi. org/10.1016/j.scitotenv.2014.05.040, consultado el 5 de septiembre de 2020

Reza, M., Eicker, U. \& Karimi, S. (2021), "Plant selection for green roofs and their impact on carbon sequestration and the building carbon footprint", Environmental Challenges, 4(November 2020), 100119. Disponible en https://doi.org/10.1016/j.envc.2021.100119, consultado el 3 de marzo de 2021.

Secretaría del Medio Ambiente (SEMA) (2016), Plan Estatal Contra el Cambio Climático en Coahuila. Disponible en http://www.gob. $\mathrm{mx} / \mathrm{cms} /$ uploads/attachment/file/106506/PECC_Coahuila_MICRO_ espa_ol_27_abril_2016.pdf, consultado el 5 de septiembre de 2020.

Sociedad Hipotecaria de la Federación (2020), Estado actual de la Vivienda en México 2019. In CIDOC y SHF (ISSUE 1). Sociedad Hipotecaria Federal. Disponible en https://www.gob.mx/shf/ documentos/86069, consultado el 25 de agosto de 2020

Trujillo Samayoa, R., Rangel Martínez, Y. \& Castañeda Nolasco, G. (2015), "Potencial del techo verde, para ahorrar electricidad por aire acondicionado en la edificación", Nova Scientia, 7(15). Disponible en http://www.redalyc.org/html/2033/203342741031/, consultado el 23 de agosto de 2020.

Vecchia, F. (1997), Clima e Ambiente construído. A abordagem dinâmica aplicada ao conforto humano. [Universidade de São Paulo]. Disponible en http://pos.fflch.usp.br/node/43547, consultado el 25 de agosto de 2020.

Vecchia, F., Castañeda, G. \& Quiroa, J. A. (2006), "Aplicación de cubiertas verdes en climas tropicales: Ensayo experimental comparativo con techumbres convencionales", Tecnología $y$ Construcción, 22(2), pp. 9-13. Disponible en http://www2. scielo.org.ve/scielo.php? script $=$ sci_arttext\&pid $=$ So798 $96012006000200002 \& \operatorname{lng}=\mathrm{es} \& \mathrm{nrm}=\mathrm{iso} \& \operatorname{lng}=\mathrm{es}$, consultado el 25 de agosto de 2020.

Watson, R., Zonyowera, M. \& Moss, R. (1996), Tecnologías, políticas y medidas para mitigar el cambio climático. Documento técnico I del IPCC. Disponible en https://archive.ipcc.ch/pdf/technicalpapers/paper-I-sp.pdf, consultado el 3 de agosto de 2020. 